\title{
Structural prerequisites for endotoxic activity in the Limulus test as compared to cytokine production in mononuclear cells
}

16(1) (2010) 39-47

(C) SAGE Publications 2010 ISSN 1753-4259 (print)

$10.1177 / 1753425909106447$

\author{
T. Gutsmann ${ }^{1}$, J. Howe ${ }^{1}$, U. Zähringer ${ }^{1}$, P. Garidel ${ }^{2}$, A.B. Schromm ${ }^{1}$, \\ M.H.J. Koch ${ }^{3}$, Y. Fujimoto ${ }^{4}$, K. Fukase ${ }^{4}$, I. Moriyon ${ }^{5}$, G. Martínez-de-Tejada ${ }^{5}$, K. Brandenburg ${ }^{1}$ \\ ${ }^{1}$ Forschungszentrum Borstel, Borstel, Germany \\ ${ }^{2}$ Universität Halle-Wittenberg, Institut für Physikalische Chemie, Halle, Germany \\ ${ }^{3}$ European Molecular Biology Laboratory, Hamburg Outstation c/o DESY, Hamburg, Germany \\ ${ }^{4}$ Department of Chemistry, Graduate School of Science, Osaka University, Toyonaka, Osaka, Japan \\ ${ }^{5}$ Department of Microbiology, Universidad de Navarra, Pamplona, Spain
}

The structural prerequisites for lipopolysaccharide (LPS) and its partial structures for the activation of the Limulus clotting cascade (Limulus amebocyte lysate [LAL] test) are described and compared with the corresponding requirements for the activation of human immune cells such as mononuclear cells. A necessary, but not sufficient, structural motif for this is the presence of the 4'-phosphate-diglucosamine backbone recognition structure ('epitope') in lipid A. High activity is only expressed by assemblies of endotoxins, but this is largely independent of the type of supramolecular aggregate structure. A particular conformation of the epitope within the lipid A assembly must be present, which is influenced by addition of further saccharide units to the lipid A moiety, but also reacts slightly to the acylation pattern. In contrast, the cytokine production of human immune cells induced by LPS sensitively depends on the type of its aggregate structure. In the case of a hexa-acylated bisphosphorylated lipid A structure, high activity is only observed with cubic inverted aggregates. Furthermore, addition of antimicrobial agents (such as polymyxin B) leads to a nearly complete inhibition of cytokine production, whereas the reduction in the Limulus assay is much lower. These data are important since a reliable determination of endotoxin concentrations, in particular with respect to its ability to elicit severe infections, is of high interest.

Keywords: structure, endotoxic activity, Limulus test, cytokine production, mononuclear cells

\section{INTRODUCTION}

Lipopolysaccharides (LPSs) belong to the most potent elicitors of the mammalian immune system due to the induction of a series of cytokines such as tumornecrosis-factor- $\alpha$ (TNF- $\alpha)$ in immunocompetent cells like mononuclear cells. ${ }^{1}$ The effects of LPS on human health may be beneficial at low concentrations to combat infectious diseases, but becomes pathological at too high a concentration leading to the severe septic shock syndrome with multi-organ failure and death, with cases numbering in the range of millions world-wide. ${ }^{2}$
It is, therefore, of utmost importance to have a reliable method for measuring the concentrations of endotoxins, for example in human body fluids.

For many years, activation of the clotting cascade from the horseshoe crab (Limulus polyphemus), Limulus amebocyte lysate (LAL), originally developed by Levin and co-workers, ${ }^{3-6}$ has been the standard and most sensitive assay to detect bacterial endotoxins. There are, however, also some limitations with this test. In a prospective study of an AMCC (Academic Medical Center Consortium) sepsis project working group, it was found that the results from the LAL test did not correlate 
with the presence of bacteremia due to Gram-negative organisms nor with mortality, but rather correlated with the presence of fungal bloodstream infection. ${ }^{7}$ This resulted from the fact that the LAL assay does not only respond to bacterial endotoxins but is also activated by the presence of $\beta$-(1 $\rightarrow 3)$-linked D-glucan, a type of polysaccharide commonly present in fungi. ${ }^{8}$ (However, commercial kits are available which avoid such activation). In previous reports, the clotting cascade was found to consist of three serine protease zymogens (factors $\mathrm{C}$ and $\mathrm{B}$ and proclotting enzyme). ${ }^{9}$ The main factor sensitive to LPS is factor $\mathrm{C}$, which was shown to react rapidly to lipid A structures such as synthetic tetra-acyl (406) and hexa-acyl (506) lipid A. ${ }^{10}$

The structural requirements for activation of the LAL test with various synthetic lipid A part structures were analysed in several studies: LAL activity correlated with progenicity but not with activation of the complement cascade, ${ }^{11}$ and the comparison of in vitro and in vivo activities showed large variations in the different test systems. ${ }^{10}$ In particular, the presence of phosphates at both the 1- and 4'-position (compound LA-15-PP or 506) gave highest activity, whereas the absence of one group (compounds $\mathrm{LA}-15 \mathrm{PH}=505$ and $\mathrm{LA}-15-\mathrm{HP}=504$ ) reduced the activity. In the LAL test compounds 506 and 504 corresponding to bisphosphoryl and 4'-monophosphoryl lipid A, respectively, were, however, nearly equally active, whereas 1-monophosphoryl lipid A was less active by one to two orders of magnitude. Furthermore, it was found that underacylated (tetraand penta-acyl) lipid A exhibited high Limulus activity (unpublished observations) whereas they were either inactive or only weakly active, respectively, in the cytokine test. ${ }^{12}$

Additionally, it was recently shown that the cytokine production induced by LPS from different species in the whole blood assay did not always correlate with the response from the LAL test. ${ }^{13}$ Experimental evidence also indicated that a particular recognition structure in the lipid A part of LPS, the 4'-monophosphoryldiglucosamine backbone, must be present for activation of the Limulus clotting cascade. ${ }^{14}$ Independently of these details, the endotoxin must be in an aggregated form for cytokine induction as well as for activation in the LAL test. ${ }^{15}$

To clarify the questions raised by the different experimental findings, a systematic study of the structural prerequisites was performed using a variety of LPSs as well as synthetic and natural lipid A analogues and partial structures. This allowed us to assign, in detail, the conformation of the recognition structure necessary for activation of the Limulus clotting cascade, and thus to determine where the LAL assay concurs or not with the whole blood assay of cytokine production.

\section{Materials AND Methods}

\section{Synthetic compounds}

The used synthetic hexa-acyl lipid A compounds 506, CM-506, and tetra-acyl lipid A 406, carboxymethylated Bis-CM-506 and Bis-CM-406 as well as monophosphoryl compounds 504 (4'-phosphate) and 505 (1-phosphate) and Kdo-505 and Kdo-506 have been described previously. ${ }^{16-21}$ The chemical structures of various lipid A analogues are presented in Figure 1.

\section{Lipids and reagents}

Lipopolysaccharides from the rough mutants Re and Ra from Salmonella enterica sv. Minnesota R595 and R60, respectively, deep rough mutant from Proteus mirabilis R45, and LPS from Yersinia pestis grown at $26^{\circ} \mathrm{C}$ and $37^{\circ} \mathrm{C}$ were extracted by the phenol/chloroform/light petroleum method ${ }^{22}$ from bacteria, purified, and lyophilized.

Lipid A was isolated from R595 LPS by mild acetate treatment and purified as described earlier. ${ }^{23}$ A pentaacyl lipid A was isolated from a mutant of Escherichia coli strain F515, which produces quantitatively only LPS with five acyl chains.

The lipid A headgroup (tetrasaccharide bisphosphate $\mathrm{TSP}_{2}$ ) was isolated from LPS (E. coli F515) after strong alkaline treatment $\left(4 \mathrm{M} \mathrm{KOH}, 100^{\circ} \mathrm{C}, 5 \mathrm{~h}\right)$ and purification of the oligosaccharides by high-performance anionexchange chromatography (HPAEC) as described elsewhere. $^{23,24}$

\section{Determination of cytokine induction}

Mononuclear cells (MNCs) were isolated from peripheral blood taken from healthy donors by the HypaqueFicoll density gradient method. The cell number was equilibrated at $5 \times 10^{6}$ cells $/ \mathrm{ml}$ RPMI 1640 containing $2 \mathrm{mM}$ L-glutamine, $100 \mathrm{U} / \mathrm{ml}$ penicillin, and $100 \mu \mathrm{g} / \mathrm{ml}$ streptomycin. For stimulation, $200 \mu 1 /$ well MNCs were transferred into 96-well culture plates. The stimuli were serially diluted in RPMI 1640 and added to the cultures at $20 \mu \mathrm{l}$ per well. The cultures were incubated for $4 \mathrm{~h}$ at $37^{\circ} \mathrm{C}$ under $5 \% \quad \mathrm{CO}_{2}$. Cell-free supernatants were collected after centrifugation of the culture plates for $10 \mathrm{~min}$ at $400 \mathrm{~g}$ and stored at $-20^{\circ} \mathrm{C}$ until determination of the cytokine content. Immunological determination of TNF- $\alpha$ in the cell supernatant was performed in a sandwich-ELISA as described earlier. ${ }^{14}$ Tumor necrosis factor- $\alpha$ was determined in duplicate at two different dilutions and the values were averaged. 


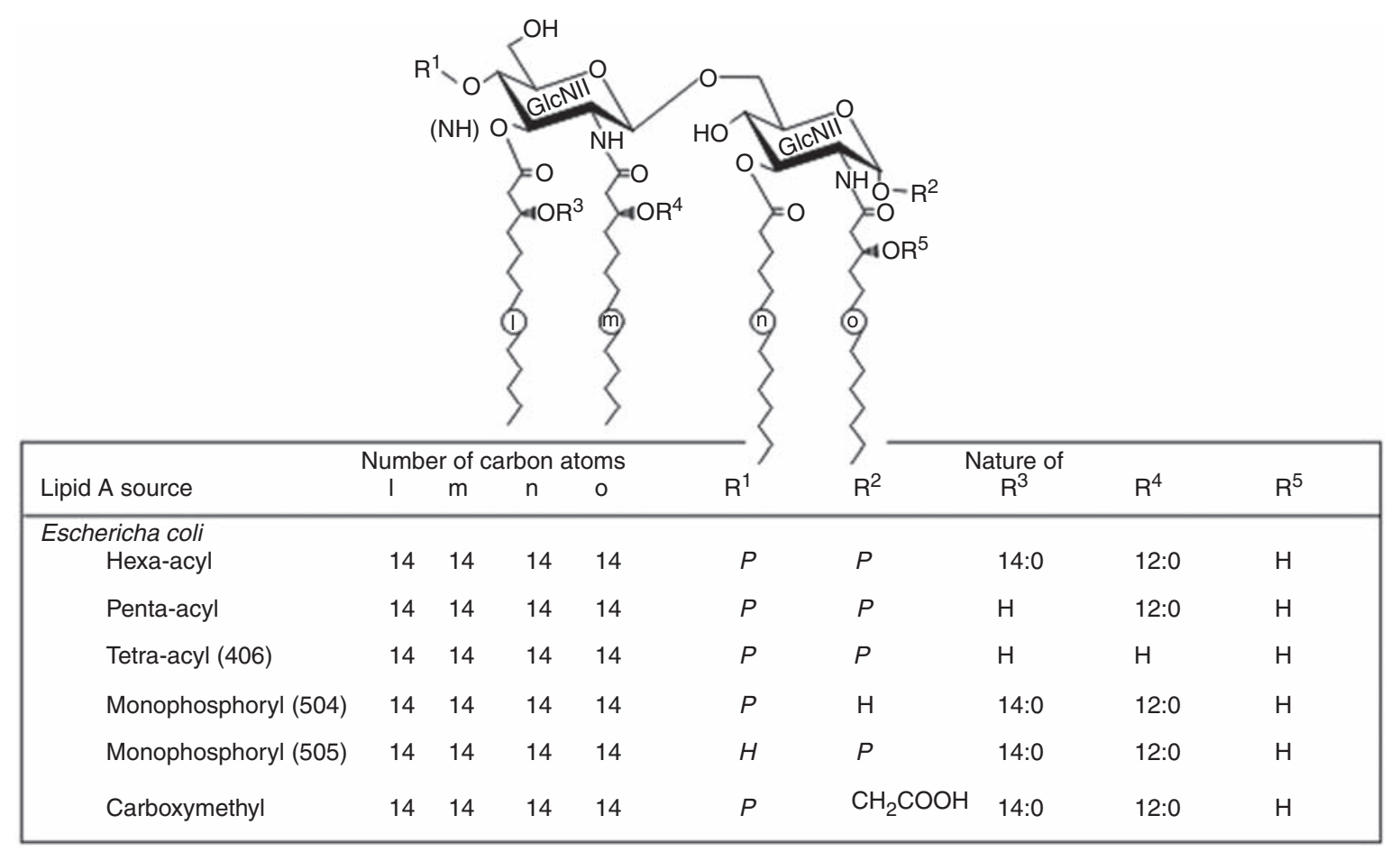

Fig. 1. Chemical structures of various lipid A analogues and partial structures used in the experiments.

Determination of endotoxin activity by the chromogenic Limulus test

Endotoxin activity of LPS and the lipid A analogs and part structures was determined by a quantitative kinetic assay based on the reactivity of Gram-negative endotoxin with Limulus amebocyte lysate (LAL) at $37^{\circ} \mathrm{C}$, using test kits of LAL Coamatic Chromo-LAL K (Chromogenix, Haemochrom). ${ }^{25}$ The standard endotoxin used in this test was from E. coli (O55:B5) and 10-15 endotoxin units (EU)/ml correspond to $1 \mathrm{ng} / \mathrm{ml}$. In this assay, saturation occurs at $50 \mathrm{EU} / \mathrm{ml}$, and the resolution limit is $>0.05 \mathrm{EU} / \mathrm{ml}$ (maximum value for ultrapure water, Aqua B. Braun).

\section{RESUlts AND Discussion}

The extreme sensitivity of the Limulus test in detecting bacterial endotoxins is presented in Figure 2A,B showing activity down to $10 \mathrm{pg} / \mathrm{ml}(0.01 \mathrm{ng} / \mathrm{ml})$ at least for Re LPS from $S$. enterica sv. Minnesota (strain R595). Lipopolysaccharide from $P$. mirabilis strain Re45 with a non-stoichiometrically bound 4-amino4deoxy-L-arabinose linked to the $4^{\prime}$-phosphate ${ }^{26}$ is significantly less active than R595 LPS (see values at $1 \mathrm{ng} / \mathrm{ml}$ and $0.1 \mathrm{ng} / \mathrm{ml}$ LPS). Lipopolysaccharide from Chromobacterium violaceum with a $3 / 3$ configuration $^{12}$ (three acyl chains are bound to the reducing and non-reducing part, respectively, of the diglucosamine) has nearly the same activity as LPS R595 except at the lowest concentrations; however, lipid A extracted from R595 LPS has clearly a reduced activity.

The activity of LPS from $Y$. pestis grown at $26^{\circ} \mathrm{C}$ and $37^{\circ} \mathrm{C}$, respectively, was compared. These strains differ in lipid A chemical structure, with the strain grown at $26^{\circ} \mathrm{C}$ having a significant amount of a hexa-acylated species, which is not found in the $37^{\circ} \mathrm{C}$ sample. ${ }^{27}$ The data of Figure 2B show a slightly higher activity of the LPS from the $37^{\circ} \mathrm{C}$ strain, but both samples have a reduced activity when compared to Re LPS from Salmonella. In contrast, the data from tests of the cytokine production in mononuclear cells show significant activity for LPS from the $26^{\circ} \mathrm{C}$ strain, but not for that grown at $37^{\circ} \mathrm{C} .{ }^{24}$

To test the influence of particular functional groups, different fragments of lipid A were investigated. In a first step, pure backbone structures were analysed, i.e. diglucosamine, $\mathrm{Kdo}_{2}-(\mathrm{GlcN})_{2}-1-\mathrm{P}\left(\mathrm{TSP}_{1}\right)$ and $\mathrm{Kdo}_{2}-$ $(\mathrm{GlcN})_{2}-1,4^{\prime}-\mathrm{P}_{2}\left(\mathrm{TSP}_{2}\right)$. The data in Figure 3 show that the pure sugar and $\mathrm{TSP}_{1}$ do not exhibit any activity, in contrast to the compound with the $4^{\prime}$-phosphate. This means that the $4^{\prime}$-phosphate in combination with the diglucosamine is the minimal structure for expression of LAL activity. Comparison with the values in Figure 2 indicates, however, that acyl chains are necessary for full expression of activity. It can be interpreted that the low activity of the pure backbone structures is due to the fact that they do not form aggregates. 
In a second step, synthetic lipid A analogues were analysed (see Fig. 1), i.e. tetra-acyl lipid A 406 and hexa-acyl lipid A 506, the corresponding variants, in which the 1-phosphate (CM-506) or both phosphates
(Bis-CM-406 and Bis-CM-506) are substituted by carboxymethyl groups, monophoyphoryl lipid A 504 (4'-phosphoryl) and 505 (1-phosphoryl), as well as the variants with Kdo substitution Kdo-505 and Kdo-506.
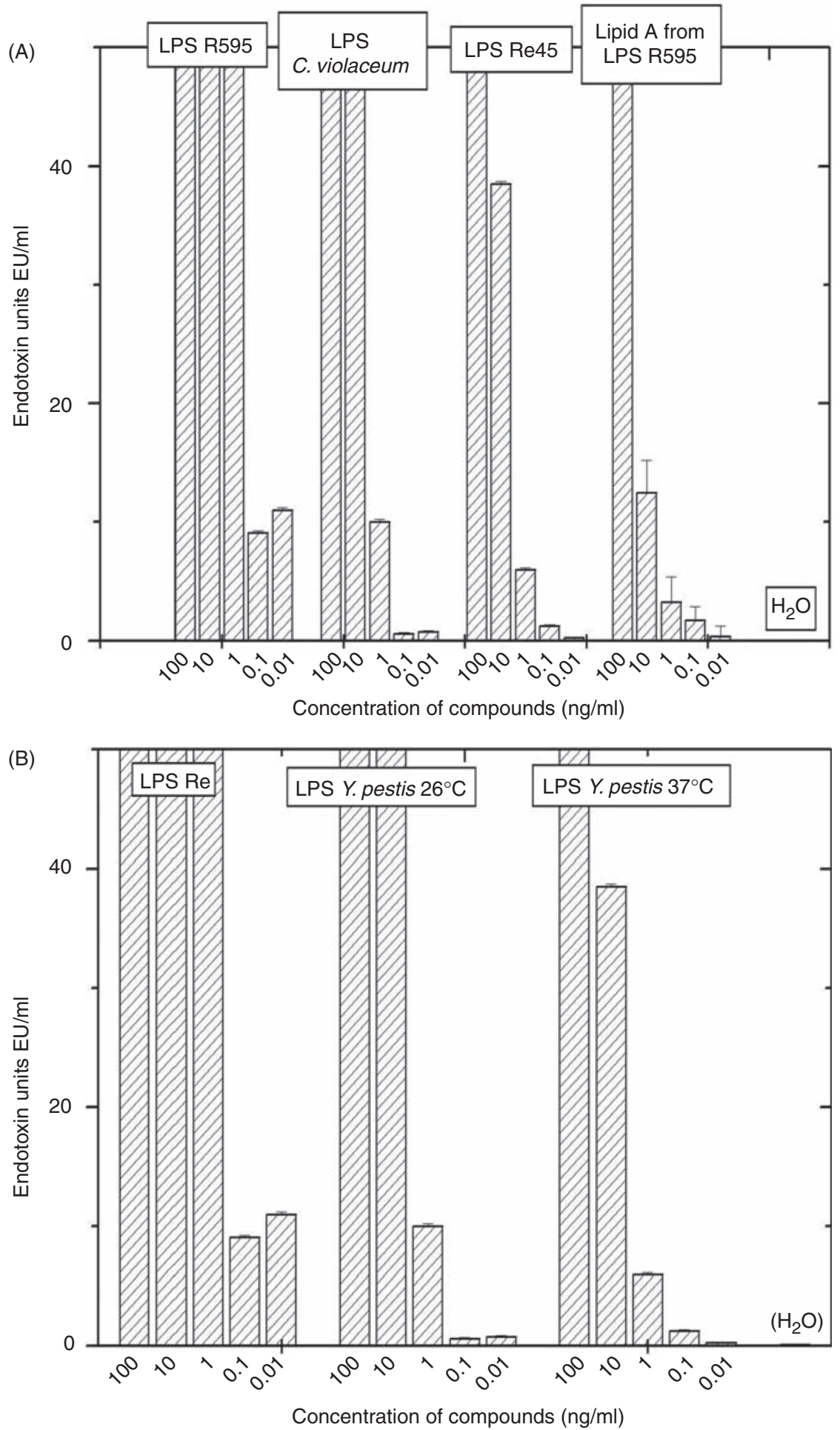

Fig. 2. Activity in the Limulus test for three different LPSs from S. enterica sv. Minnesota R595, P. mirabilis R45, Chromobacterium violaceum, and lipid A from LPS R595 (A), and for LPS R595 in comparison to LPS from Y. pestis grown at $26^{\circ} \mathrm{C}$ and $37^{\circ} \mathrm{C}$ (B). 
The data in Table 1 prove high activity for compound 406, followed by 506. Compound CM-506 still has high activity, whereas compounds lacking phosphates exhibit reduced activity, but are not inactive. Interestingly, the samples 505 and Kdo-505 which have no 4'-phosphate are nearly inactive.

The data in Table 1 give clear evidence that the acylation pattern for compounds with a diglucosamine4'-phosphate backbone only marginally influences LAL activity, i.e. compounds 406, 506, Kdo-506, 504, and triacyl lipid A have comparable activity. These compounds may differ in their aggregate structures (taken from the literature $^{12,28,29}$ and unpublished observations). The aggregate structures vary from lamellar (L) over mixed

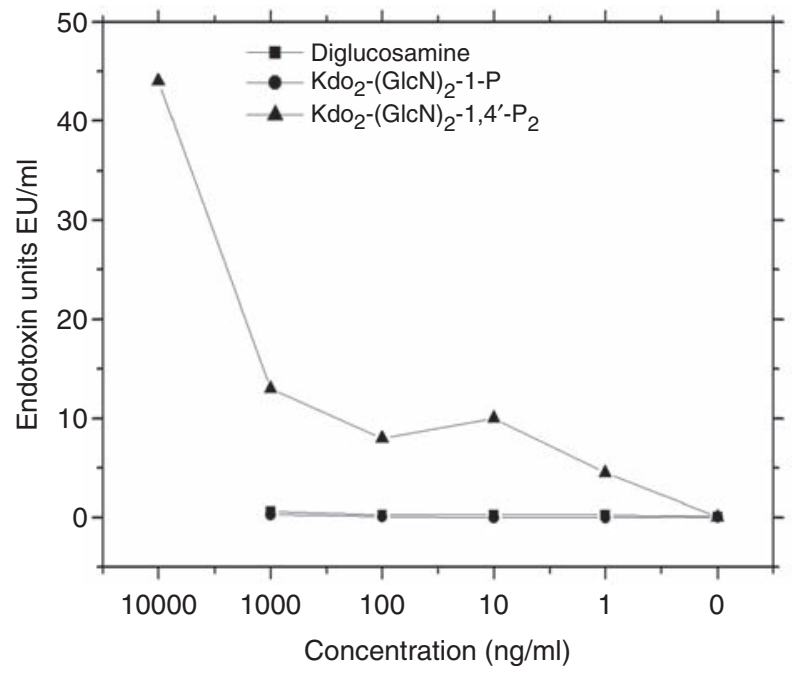

Fig. 3. Activity in the Limulus test for lipid A backbone fragments diglucosamine, $\mathrm{TSP}_{1}\left[\mathrm{Kdo}_{2}-(\mathrm{GlcN})_{2}-1-\mathrm{P}\right)$, and $\mathrm{TSP}_{2}\left(\mathrm{Kdo}_{2}-(\mathrm{GlcN})_{2}-\right.$ $\left.1,4^{\prime}-\mathrm{P}_{2}\right)$. cubic-lamellar $(\mathrm{Q} / \mathrm{L})$ and pure cubic $(\mathrm{Q})$ to micellar $(\mathrm{M})$ ones (data from the literature ${ }^{28,29}$ ). Clearly, the type of aggregate structure only marginally, if at all, influences the reactivity in the Limulus test. The data show, furthermore, that the existence of a diglucosamine is a necessary feature for activation. Indeed, analysis of the monosaccharide part structures GLA-58 and GLA-69 corresponding to the non-reducing part of lipid A gives very low activity, when one of the glucosamine monosaccharides is missing. The data for tri-acyl lipid A with both phosphates indicate that three acyl chains are sufficient to provide nearly full activity (Table 1). When comparing these values with those from the acyl chain-free compounds (Fig. 3), it becomes clear, however, that acyl chains are required for high LAL activity.

A comparison of the LAL data with published results from the cytokine expression in mononuclear cells induced by these compounds (right column in Table 1, see the literature ${ }^{30,31}$ ) gives clear evidence that, in the human immune cell system, the aggregate structure of LPS is the decisive feature: only compounds adopting cubic inverted structures are highly active. Differences in cytokine expression of compounds with cubic structures result from differences in acyl chain mobility as outlined earlier. ${ }^{32}$

The differences observed in the two biological test systems is in accordance with the results of Dehus et al., ${ }^{13}$ who found that the whole blood assay 'does not always correlate' with the Limulus test for the immune stimulatory potency of 11 different LPS samples from entero- as well as non-enterobacterial origin; for example, the comparison of LPS from Pseudomonas aeruginosa with that from S. enterica sv. Abortus equi showed an overestimation of the pyrogenic burden by a

Table 1. Endotoxic activity in the LAL test, aggregate structures (Q, cubic; L, lamellar; M, micellar), and cytokineinducing activity of various synthetic lipid A analogues and partial structures as compared to LPS R595 (LPS Re)

\begin{tabular}{lllllllll}
\hline $\begin{array}{l}\text { Concentration } \\
\text { lipid }\end{array}$ & $1 \mu \mathrm{g} / \mathrm{ml}$ & $100 \mathrm{ng} / \mathrm{ml}$ & $10 \mathrm{ng} / \mathrm{ml}$ & $1 \mathrm{ng} / \mathrm{ml}$ & $100 \mathrm{pg} / \mathrm{ml}$ & $\begin{array}{l}\text { Aggregate } \\
\text { structure }\end{array}$ & $\begin{array}{l}\text { Cytokine } \\
\text { expression }\end{array}$ & $\begin{array}{l}\text { Aggregate } \\
\text { structure }\end{array}$ \\
\hline LPS Re & $>50$ & 21.5 & 3.4 & 1.3 & 0.2 & $\mathrm{Q}$ & +++++ & $\mathrm{Q}$ \\
406 & $>50$ & $>50$ & $>50$ & 18.3 & 0.8 & $\mathrm{~L}$ & - & $\mathrm{L}$ \\
Bis-CM-406 & $>50$ & 24.6 & 4.5 & 0.7 & 0.4 & $\mathrm{~L}$ & - & $\mathrm{L}$ \\
506 & $>50$ & 46.5 & 15.4 & 2.2 & 0.3 & $\mathrm{Q}$ & ++++ & $\mathrm{Q}$ \\
CM-506 & & $>50$ & 9.4 & 4.7 & 0.9 & $\mathrm{Q}$ & ++++ & $\mathrm{Q}$ \\
Bis-CM-506 & $>50$ & 15 & 5 & 1.8 & 0.6 & $\mathrm{Q}$ & +++ & $\mathrm{Q}$ \\
Kdo-506 & & $>50$ & $>50$ & 25.5 & 5.2 & $\mathrm{Q}$ & ++++ & $\mathrm{Q}$ \\
504 & $>50$ & $>50$ & 18.8 & 6.5 & 3.5 & $\mathrm{Q} / \mathrm{L}$ & +++ & $\mathrm{Q} / \mathrm{L}$ \\
505 & 1.3 & 0.2 & 0.1 & - & - & $\mathrm{Q} / \mathrm{L}$ & +++ & $\mathrm{Q} / \mathrm{L}$ \\
Kdo-505 & 12 & 1.3 & 0.1 & - & - & $\mathrm{Q} / \mathrm{L}$ & +++ & $\mathrm{Q} / \mathrm{L}$ \\
GLA-58 & 10 & 1.2 & 0.2 & - & - & $\mathrm{L}$ & - & $\mathrm{L}$ \\
GLA-69 & 0.8 & 0.4 & 0.1 & - & - & $\mathrm{Q}$ & ++ & $\mathrm{Q}$ \\
Triacyl lipid A & $>50$ & $>50$ & 6.5 & 1.5 & 0.15 & $\mathrm{M}$ & - & $\mathrm{M}$ \\
\hline
\end{tabular}


factor of 500 in the LAL test when compared with the cell assay.

The interaction between LPS and the purified factor C from Tachypleus tridentatus studied by Nakamura et $a l .{ }^{33}$ showed that the detergent Triton-X, which destroys LPS aggregates, inhibited the LPS-mediated binding of factor $\mathrm{C}$. This gives clear evidence that the aggregated form of LPS is responsible for binding to factor $\mathrm{C}$, and this is what has been found explicitly in previous reports, in which the comparison of monomeric and aggregated forms of lipid A and LPS exhibited a high activity for the latter but no activity in the former administration. ${ }^{15}$

Since the LAL assay is frequently used to test the effectiveness of antimicrobial drugs for the neutralization of LPS, the action of the 'gold standard' polymyxin $\mathrm{B}$ (PMB) on the response in the Limulus test was also monitored (Fig. 5) and compared with the respective results in the cell assay (Fig. 4). The data in Figure 4 show that a significant reduction of the LAL activity is observed only at the lowest concentration of Ra LPS $(1 \mathrm{ng} / \mathrm{ml})$, both at an excess of 10:1 and 100:1 weight percent PMB:LPS. In contrast, the results from the cytokine expression in human mononuclear cells exhibit high inhibition values at all LPS concentrations and both LPS:PMB ratios. Similar data were obtained also for LPS Re45, a deep rough mutant LPS from the PMBresistant strain P. mirabilis R45, and for free lipid A from S. enterica sv. Minnesota R595 LPS. The cell assay data give clear evidence that PMB reduces cytokine expression similar to that found for Ra LPS (data not shown). In contrast, the LAL reactivity, although reduced, still shows considerable response (Fig. 6).

It has been shown that the aggregate structures of lipid A or LPS convert in the presence of antimicrobial agents such as PMB from a cubic or mixed cubic/unilamellar form into a multilamellar organisation. ${ }^{34,35}$ Therefore, as described above for the compounds which are a priori inactive (e.g. compound 406), the existence of the multilamellar aggregate form is a necessary prerequisite for endotoxin inactivity/inactivation in producing cytokines. $^{25,36}$

The clotting cascade consists of three serine protease zymogens (factors $\mathrm{C}$ and $\mathrm{B}$ and proclotting enzyme). ${ }^{9}$ The recognition structure within the Limulus clotting cascade, factor C, can bind to the 4'-phosphate-diglucosamine part of lipid A/LPS also in the presence of added antimicrobial agents. This LPS-sensitive serine-protease was found to be a novel type of serine protease ${ }^{37}$ and, as initiator of the hemolymph coagulation system after binding to LPS, is expressed in a nearly identical form in the American horseshoe crab Limulus polyphemus as in the east Asian crab Tachypleus tridentatus. ${ }^{38}$ Factor $\mathrm{C}$ with a molecular mass (MM) of $123,000 \mathrm{~g} / \mathrm{mol}$,

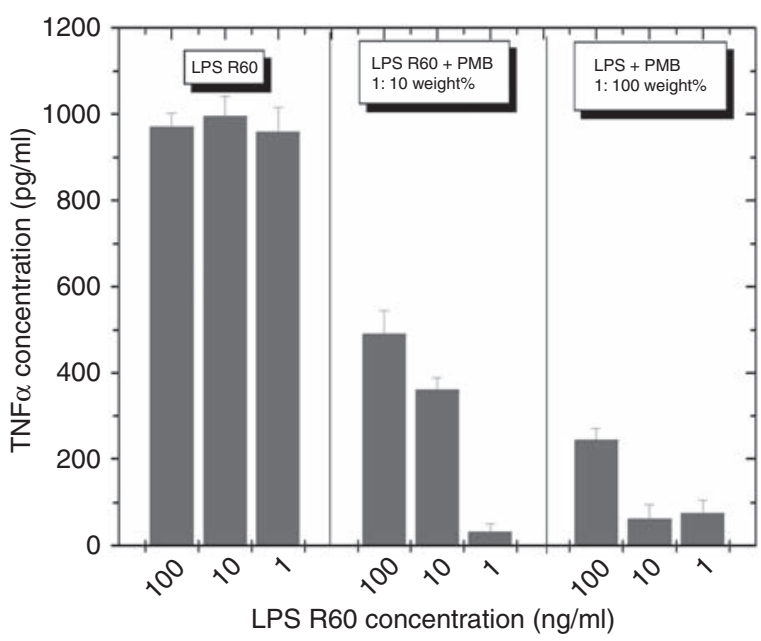

Fig. 4. Production of TNF- $\alpha$ by LPS from $S$. enterica sv. Minnesota R60 (with complete core oligosaccharide) at three different concentrations in the absence and presence of polymyxin $\mathrm{B}$ at [LPS]:[PMB] 1:10 and 1:100 weight percent, respectively.

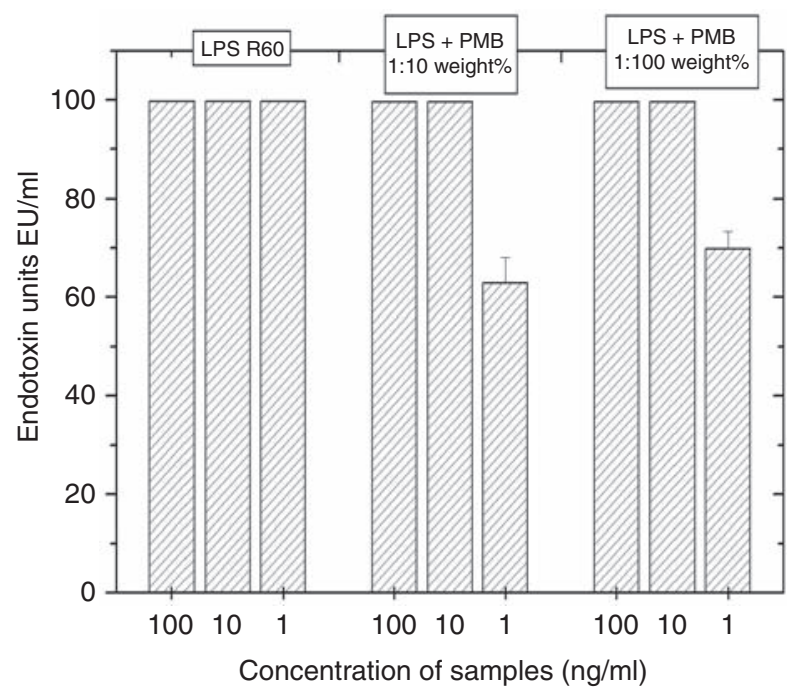

Fig. 5. Activity in the Limulus test for LPS from S. enterica sv. Minnesota R60 (with complete core oligosaccharide) at three different concentrations in the absence and presence of polymyxin $\mathrm{B}$ at [LPS]:[PMB] 1:10 and 1:100 weight percent, respectively.

consisting of a light chain $(\mathrm{MM}=43000 \mathrm{~g} / \mathrm{mol})$ and a heavy chain ( $\mathrm{MM}=80000 \mathrm{~g} / \mathrm{mol})$, is converted into an activated form in the presence of LPS. ${ }^{33}$ It associates with LPS on the hemocyte surface which is induced by the binding of a cysteine-rich region to LPS. Upon activation, the light chain is cleaved which leads to accumulation of two new fragments. Factor $\mathrm{C}^{*}$ then activates factor $\mathrm{B}$ to $\mathrm{B}^{*}$, which in turn converts the proclotting enzyme to the clotting enzyme. In a final step, the clotting enzyme coagulogen, a soluble protein, is converted into an insoluble coagulin gel. 
(A)

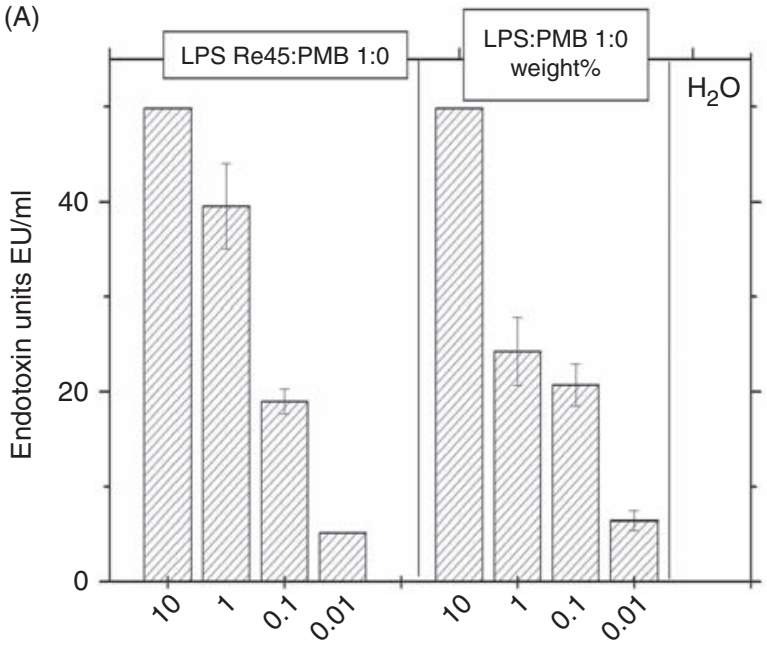

LPS concentration ( $\mathrm{ng} / \mathrm{ml})$

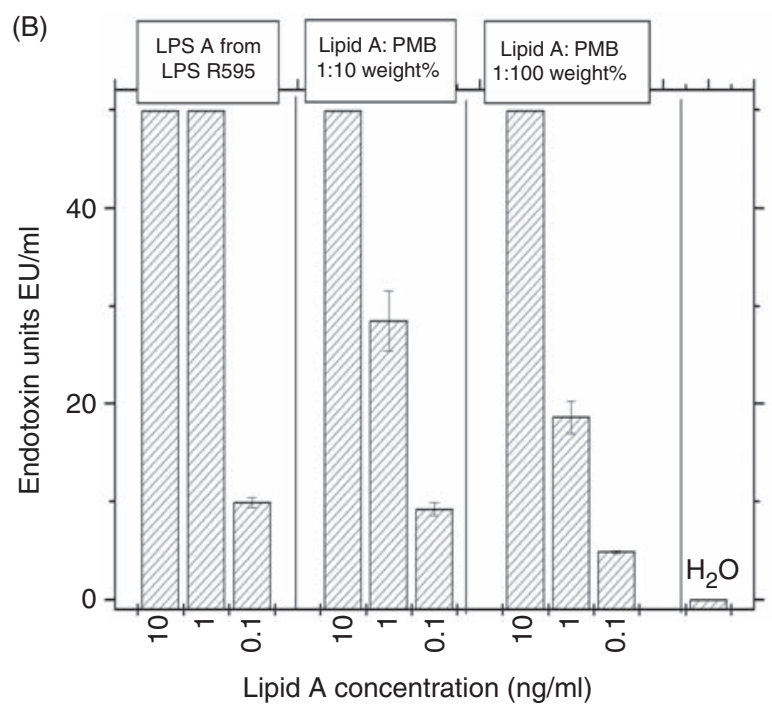

Fig. 6. Activity in the Limulus test for LPS from P. mirabilis R45 (A) and lipid A from LPS R595 (B) in the absence and presence of polymyxin $\mathrm{B}$ at [LPS]:[PMB] 1:10 and 1:100 weight percent, respectively.

In accordance with our data, Nakamura et al..$^{38}$ found that the zymogen factor $C$ is rapidly activated by an acylated $\beta$ - $(1 \rightarrow 6)$-linked D-glucosamine disaccharide bisphosphate, and the corresponding 4'-monophosphate; for this, they used tetra- and hexa-acylated lipid A analogs with variations in the phosphate substitution 403 to 406 and 503 to 506, respectively. Their observation that compounds having only the 1-phosphate diglucosamine backbone (405 and 505, respectively) are much less potent in activating factor $\mathrm{C}$ is in agreement with our data (Table 1). They reported, furthermore, that the tetraacylated compounds were more active than the hexaacylated compounds to activate factor $\mathrm{C}$, which corresponds to our results in the comparison of 406 and 506. The comparison of compound 506 and Kdo-506 (Table 1) as well as of the two Yersinia-LPSs (Fig. 2B) indicates that the acylation pattern alone is not sufficient to explain differences in activity. The presence of the Kdo moiety and further sugars apparently leads to a more favorable conformation of the lipid A backbone thus enhancing the accessibility for factor $\mathrm{C}$. This is also clear when comparing Re LPS and lipid A derived from it, indicating a higher activity of the former (Fig. 2A). It is also noteworthy that the additional substitution with an amino-arabinose at the $4^{\prime}$-phosphate for LPS Re45 reduces the activity without inhibiting it (Fig. 2A).

\section{CONCLUSIONS}

It is clear that the diglucosamine-4'phosphate is the decisive epitope in the LAL test. The absent or strongly reduced (Fig. 3) activity in the monomeric state indicates that aggregates of the endotoxins are required. The type of aggregate structure is, however, not a determinant of Limulus activity. It remains a task for the future to study the precise molecular conformation of lipid A within LPS aggregates necessary to stimulate factor $\mathrm{C}$.

The prerequisites for the activation of immune cells by endotoxins are different from those for activation of the LAL cascade: In this case, endotoxin aggregates with a suitable endotoxin conformation where the lipid A part adopts a conical wedge-shaped conformation with a smaller cross-section of the backbone compared to that of the hydrophobic part, interact with binding proteins such as lipopolysaccharide-binding protein and CD14. This leads to intercalation of the endotoxins into the target cell membranes, where the endotoxins form domains which strongly disturb the membrane architecture leading to cell activation at the site of transmembrane proteins such as the TLR4/MD2 system.

Our data are of utmost interest with respect to the use of the LAL test in monitoring the success of an antimicrobial therapy in patients. As the data show, the Limulus test may indicate false negative values, although LPS-induced cytokine production is considerably inhibited. This means that the LAL test is not necessarily a reliable assay in therapeutic agents.

\section{ACKNOWLEDGEMENTS}

The authors are indebted to U. Diemer, N. Hahlbrock, and K. Stephan for support in the LAL test and the cytokine production test system, and the German Ministry for Education and Science (BMBF) for financial support (project GU 0824). 


\section{REFERENCES}

1. Rietschel ETh, Kirikae T, Schade FU et al. Bacterial endotoxin: molecular relationships of structure to activity and function. FASEB J 1994; 8: 217-225.

2. Rietschel ET, Brade $\mathrm{H}$, Holst $\mathrm{O}$ et al. Bacterial endotoxin: chemical constitution, biological recognition, host response, and immunological detoxification. Curr Top Microbiol Immunol 1996; 216: 39-81.

3. Roth RI, Su D, Child AH, Wainwright NR, Levin J. Limulus antilipopolysaccharide factor prevents mortality late in the course of endotoxemia. J Infect Dis 1998; 177: 388-394.

4. Roth RI, Levin J. Purification of Limulus polyphemus proclotting enzyme. J Biol Chem 1992; 267: 24097-24102.

5. Roth RI, Levin FC, Levin J. Optimization of detection of bacterial endotoxin in plasma with the Limulus test. J Lab Clin Med 1990; 116: $153-161$.

6. Levin J. The Limulus amebocyte lysate test: perspectives and problems. Prog Clin Biol Res 1987; 231: 1-23.

7. Bates DW, Parsonnet J, Ketchum PA et al. Limulus amebocyte lysate assay for detection of endotoxin in patients with sepsis syndrome. AMCC Sepsis Project Working Group. Clin Infect Dis 1998; 27: 582-591.

8. Tanaka S, Iwanaga S. Limulus test for detecting bacterial endotoxins. Methods Enzymol 1993; 223: 358-364.

9. Nakamura T, Tokunaga F, Morita T, Iwanaga S. Interaction between lipopolysaccharide and intracellular serine protease zymogen, factor $\mathrm{C}$, from horseshoe crab (Tachypleus tridentatus) hemocytes. J Biochem 1988; 103: 370-374.

10. Takada H, Kotani S. Structural requirements of lipid A for endotoxicity and other biological activities. CRC Crit Rev Microbiol 1989; 16: 477-523.

11. Takada H, Kotani S, Tanaka S et al. Structural requirements of lipid A species in activation of clotting enzymes from the horseshoe crab, and the human complement cascade. Eur $J$ Biochem 1988; 175: 573-580.

12. Schromm AB, Brandenburg K, Loppnow $\mathrm{H}$ et al. Biological activities of lipopolysaccharides are determined by the shape of their lipid A portion. Eur J Biochem 2000; 267: 2008-2013.

13. Dehus O, Hartung T, Hermann C. Endotoxin evaluation of eleven lipopolysaccharides by whole blood assay does not always correlate with Limulus amebocyte lysate assay. J Endotoxin Res 2006; 12: 171-180.

14. Brandenburg K, Jürgens G, Andrä J et al. Biophysical characterization of the interaction of high-density lipoprotein (HDL) with endotoxins. Eur J Biochem 2002; 269: 5972-5981.

15. Mueller M, Lindner B, Kusumoto S, Fukase K, Schromm AB, Seydel U. Aggregates are the biologically active units of endotoxin. J Biol Chem 2004; 279: 26307-26313.

16. Imoto $M$, Yoshimura $H$, Yamamoto $M$, Shimamoto $T$, Kusumoto K, Shiba T. Chemical synthesis of a biosynthetic precursor of lipid A. Bull Chem Soc Jpn 1987; 60: 2197-2204.

17. Liu W-C, Oikawa M, Fukase K, Suda Y, Kusumoto S. A divergent synthesis of lipid A and its chemically stable unnatural analogues. Bull Chem Soc Jpn 1999; 72: 1377-1385.

18. Kusumoto S, Fukase K, Fukase Y et al. Structural basis for endotoxic and antagonistic activities: investigation with novel synthetic lipid A analogs. J Endotoxin Res 2003; 9: 361-366.

19. Kusumoto S, Fukase K, Fukase Y et al. Structural basis for endotoxic and antagonistic activities: investigation with novel synthetic lipid A analogs. J Endotoxin Res 2003; 9: 361-366.
20. Yoshizaki H, Fukuda N, Sato K et al. First total synthesis of the Re-type lipopolysaccharide. Angew Chem Int Edn 2001; 40: $1475-1480$.

21. Kusumoto S, Fukase K, Fujimoto Y. Synthesis of lipopolysaccharide, peptidoglycan, and lipoteichoic acid fragments. London: Elsevier, 2008; 685-711.

22. Galanos C, Lüderitz O, Westphal O. A new method for the extraction of R lipopolysaccharides. Eur J Biochem 1969; 9: 245-249.

23. Zähringer U, Salvetzki R, Ulmer AJ, Rietschel ETh. Isolation, chemical analysis and biological investigations of natural lipid A and lipid A-antagonists. J Endotoxin Res 1996; 3 (Suppl. 1): 33.

24. Zähringer U, Sinnwell V, Peter-Katalinic J, Rietschel ET, Galanos C. Isolation and characterization of the tetrasaccharide (bis)phosphate from the glycosyl backbone of Salmonella enterica sv. Minnesota and Escherichia coli Re-mutant lipopolysaccharides. Tetrahedron 1993; 49: 4193-4200.

25. Andrä J, Lamata M, Martinez DT, Bartels R, Koch MH, Brandenburg K. Cyclic antimicrobial peptides based on Limulus anti-lipopolysaccharide factor for neutralization of lipopolysaccharide. Biochem Pharmacol 2004; 68: 1297-1307.

26. Zähringer U, Lindner B, Rietschel ET. Chemical structure of lipid A. Recent advances in structural analysis of a biologically active molecules. In: Brade H, Opal SM, Vogel SN, Morrison DC., (eds) Endotoxin in Health and Disease. New York: Marcel Dekker, 1999; 93-114.

27. Rebeil R, Ernst RK, Gowen BB, Miller SI, Hinnebusch BJ. Variation in lipid A structure in the pathogenic Yersiniae. Mol Microbiol 2004; 52: 1363-1373.

28. Brandenburg K, Kusumoto S, Seydel U. Conformational studies of synthetic lipid A analogues and partial structures by infrared spectroscopy. Biochim Biophys Acta 1997; 1329: 193-201.

29. Seydel U, Schromm AB, Brade L et al. Physicochemical characterization of carboxymethyl lipid A derivatives in relation to biological activity. FEBS J 2005; 272: 327-340.

30. Brandenburg K, Andrä J, Müller M, Koch MHJ, Garidel P. Physicochemical properties of bacterial glycopolymers in relation to bioactivity. Carbohydr Res 2003; 338: 2477-2489.

31. Brandenburg K, Wiese A. Endotoxins: relationships between structure, function, and activity. Curr Top Med Chem 2004; 4: $1127-1146$.

32. Garidel P, Rappolt M, Schromm AB et al. Divalent cations affect chain mobility and aggregate structure of lipopolysaccharide from Salmonella minnesota reflected in a decrease of its biological activity. Biochim Biophys Acta 2005; 1715: 122-131.

33. Nakamura $\mathrm{T}$, Tokunaga $\mathrm{F}$, Morita $\mathrm{T}$ et al. Intracellular serineprotease zymogen, factor $\mathrm{C}$, from horseshoe crab hemocytes. Its activation by synthetic lipid A analogues and acidic phospholipids. Eur J Biochem 1988; 176: 89-94.

34. Brandenburg K, Moriyon I, Arraiza MD, Lehwark-Yvetot G, Koch MHJ, Seydel U. Biophysical investigations into the interaction of lipopolysaccharide with polymyxins. Thermochim Acta 2002; 382: 189-198.

35. Brandenburg K, David A, Howe J, Koch MH, Andrä J, Garidel P. Temperature dependence of the binding of endotoxins to the polycationic peptides polymyxin $\mathrm{B}$ and its nonapeptide. Biophys J 2005; 88: 1845-1858.

36. Andrä J, Gutsmann T, Garidel P, Brandenburg K. Mechanisms of endotoxin neutralization by synthetic cationic compounds. J Endotoxin Res 2006; 12: 261-277.

37. Tokunaga F, Miyata T, Nakamura $\mathrm{T}$ et al. Lipopolysaccharidesensitive serine-protease zymogen (factor C) of horseshoe crab 
hemocytes. Identification and alignment of proteolytic fragments produced during the activation show that it is a novel type of serine protease. Eur J Biochem 1987; 167: 405-416.

38. Nakamura $\mathrm{T}$, Tokunaga $\mathrm{F}$, Morita $\mathrm{T}$, Iwanaga S. Interaction between lipopolysaccharide and intracellular serine protease zymogen, factor $\mathrm{C}$, from horseshoe crab (Tachypleus tridentatus) hemocytes. J Biochem 1988; 103: 370-374.
39. Brandenburg $\mathrm{K}$, Matsuura $\mathrm{M}$, Heine $\mathrm{H}$ et al. Biophysical characterization of triacyl monosaccharide lipid A partial structures in relation to bioactivity. Biophys $J$ 2002; 83: 322-333.

40. Brandenburg K, Lindner L, Schromm AB. Physico-chemical characteristics of triacyl lipid A partial structure OM-174 in relation to biological activity. Eur J Biochem 2000; 267: 3370-3377. 